\title{
Magnetotelluric image of the fluid cycle in the Costa Rican subduction zone
}

\author{
Tamara Worzewski ${ }^{1 \star}$, Marion Jegen ${ }^{1}$, Heidrun Kopp ${ }^{1,2}$, Heinrich Brasse ${ }^{3}$ and Waldo Taylor ${ }^{4}$
}

Fluids entering the subduction zone play a key role in the subduction process. They cause changes in the dynamics and thermal structure of the subduction zone', and trigger earthquakes when released from the subducting plate during metamorphism ${ }^{2,3}$. Fluids are delivered to the subduction zone by the oceanic crust and also enter as the oceanic plate bends downwards at the plate boundary. However, the amount of fluids entering subduction zones is not matched by that leaving through volcanic emissions ${ }^{4}$ or transfer to the deep mantle ${ }^{2}$, implying possible storage of fluids in the crust. Here we use magnetotelluric data to map the entire hydration and dehydration cycle of the Costa Rican subduction zone to $120 \mathrm{~km}$ depth. Along the incoming plate bend, we detect a conductivity anomaly that we interpret as sea water penetrating down extensional faults and cracks into the upper mantle. Along the subducting plate interface we document the dehydration of sediments, the crust and mantle. We identify an accumulation of fluids at $\sim 20-30 \mathrm{~km}$ depth at a distance of $30 \mathrm{~km}$ seaward from the volcanic arc. Comparison with other subduction zones ${ }^{5-14}$ indicates that such fluid accumulation is a global phenomenon. Although we are unable to test whether these fluid reservoirs grow with time, we suggest that they can account for some of the missing outflow of fluid at subduction zones.

Oceanic crust and lithosphere is hydrated during its creation at mid-ocean ridges ${ }^{15}$. Hydration has also been proposed to occur at subduction zones related to the bending of the oceanic plate, which causes extension and normal faulting reaching several kilometres depth below the crust-mantle boundary as inferred from seismic and thermal investigations ${ }^{16,17}$. Recent numerical experiments show how stress changes induced by the bending oceanic plate can produce vertical pressure gradients along normal faults, favouring downward pumping of fluids and enabling fluids to penetrate to great depths despite their natural buoyancy ${ }^{18}$. On subduction, fluids in the hydrated slab are released in a series of metamorphic reactions ${ }^{2,6}$, but their distribution is not well constrained by existing data. Fluid accumulation is associated with electrically low-resistive (conductive) anomalies, because the bulk electrical resistivity of a rock is mainly governed by the amount of interconnected fluid present ${ }^{19}$. We use the term fluids for partial melt and for water originated from pores and fractures or from mineral-bound water. Electromagnetic methods, such as magnetotellurics, are sensitive to electric conductivity anomalies associated with fluids and have therefore been widely used to image fluid migration and melt pathways (for example refs 5,6,20).

Numerical studies have shown that onshore-offshore data are a prerequisite to image the hydration-dehydration cycle in subduction zones ${ }^{21}$. Nearly all previous magnetotellurics surveys

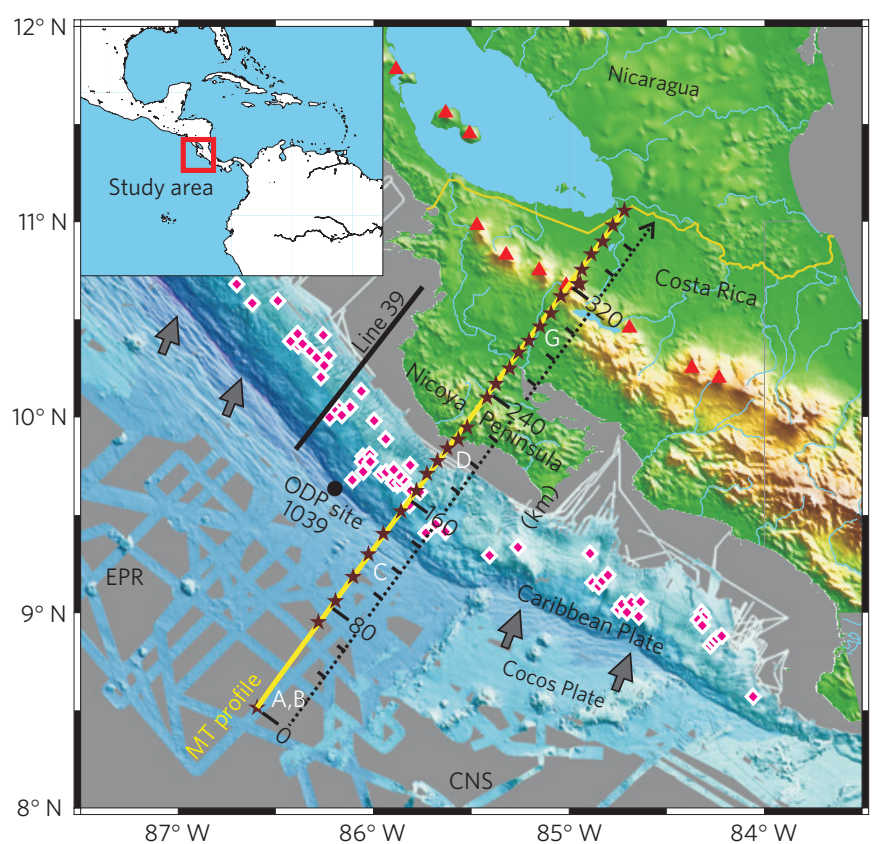

Figure 1 | Location of magnetotelluric profile on- and offshore Nicoya Peninsula in Costa Rica. Black stars on the yellow profile show station positions. Red triangles: volcanoes. Black dot: borehole position of Ocean Drilling Program Leg 170 Site 1039. Black line: bathymetric profile (Line 39) of ref. 16. Grey letters on kilometre markers refer to observed anomalies in Fig. 2. Pink diamonds: fluid seeps. Arrows indicate the direction of plate convergence (for further information see Supplementary Information).

on subduction zones were limited to either exclusively land (for example refs 6,20) or marine acquisition (for example ref. 7).

An exception was constituted in the Cascadia subduction zone through the pioneering EMSLAB project in the 1980s (refs 8, 22), which at the time was the largest electromagnetic study incorporating land as well as marine measurements. Hydration processes were not confirmed, because only a few magnetotelluric responses around the trench could be incorporated, but other conductive structures were identified that were attributed to fluids in the subduction zone.

The Costa Rica subduction zone has been widely studied in many aspects involving fluids (see, for example, refs 16,23,24). Offshore Costa Rica, the Cocos plate that is generated at the East Pacific Rise in the west and the Cocos-Nazca Spreading Centre in the south, is thrust beneath the Caribbean plate (Fig. 1) at a rate of approx. $88 \mathrm{~km} \mathrm{Myr}^{-1}$. Ref. 25 has imaged the seismogenic zone extending down to $26-28 \mathrm{~km}$ underneath Nicoya Peninsula. 

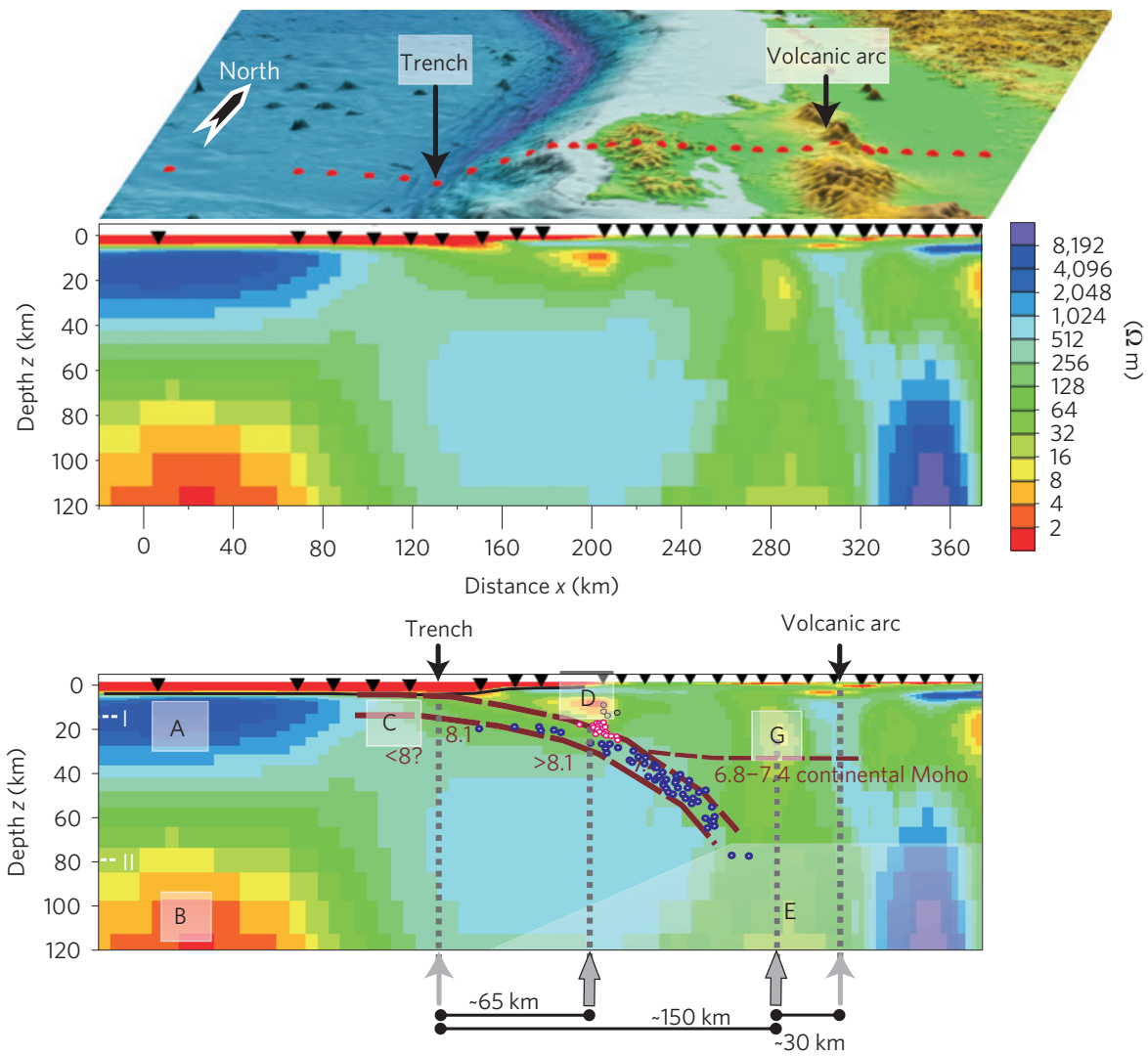

Figure 2 | Two-dimensional inversion model of electrical resistivity below the Costa Rican subduction zone. Upper panel: station map including bathymetry. For the location, refer to Fig. 1. Middle panel: inversion result. The electrical resistivity given in ohm metre ranges from conductive (least resistive) in red to highly resistive in blue, that is, red to yellow colours indicate high to moderate conductivity (low resistivity) associated with fluids. The colour scale is logarithmic. Lower panel: seismic information superimposed on inversion result-seismic boundaries (dashed brown) and velocities; blue circles, interplate earthquakes; pink circles, seismogenic-zone earthquakes from ref. 25. The transparent area is of limited significance owing to lower resolution. I and II indicate transition to the mantle and electrical asthenosphere, respectively.

In 2007-2008 we conducted a long-period magnetotellurics experiment along a 380-km-long profile extending onshoreoffshore Nicoya Peninsula with a station spacing dense enough to resolve conductive structures that were small compared with profile length.

The onshore-offshore magnetotellurics data were inverted to provide a comprehensive electrical resistivity image of the deep Costa Rican subduction zone, enabling us to image both hydration and fluid release from the incoming oceanic plate into the overriding plate.

The farthermost marine stations southwest of the trench image normal oceanic lithosphere in terms of electrical resistivity (anomaly A in Fig. 2), as has also been observed in other marine magnetotellurics surveys (for example at the East Pacific Rise ${ }^{26}$ ). Low-resistive $(<10 \Omega \mathrm{m})$, water-saturated oceanic sediments overlay pillow lavas and sheeted dykes with increasing resistivities until a very high resistivity $(>1,000 \Omega \mathrm{m})$ is reached in the upper mantle. At lithospheric depths beneath $40 \mathrm{~km}$, resistivities decrease again owing to increasing temperatures ${ }^{27}$. Low-resistive anomaly B in Fig. 2 beneath $\sim 80 \mathrm{~km}$ depth is consistent with other oceanic magnetotellurics studies on oceanic plates ${ }^{28}$, and could possibly be associated with an asthenosphere containing minor amounts of partial melts.

On underthrusting, the highly resistive oceanic lithosphere exhibits a moderate reduction in electrical resistivity down to deepcrustal and possibly upper-mantle regions $(>1,000 \Omega \mathrm{m}$ to $\sim 50 \Omega \mathrm{m}$ anomaly C in Fig. 2). Multibeam bathymetry and multichannel seismic reflection images northwest of Nicoya Peninsula ('Line 39' in Fig. 1) reveal that bending-related faulting of the incoming plate creates a pervasive tectonic fabric, penetrating at least $20 \mathrm{~km}$ into the crust and upper mantle, promoting serpentinization of the upper mantle ${ }^{16}$. Reduced seismic velocities in the upper mantle along a seismic refraction array ${ }^{25}$ also point to serpentinized mantle but could not be resolved well because of a lack of ocean-bottom seismometers. Serpentinization of the mantle produces an increase in porosity leading to a reduction in electrical resistivity ${ }^{29}$, which may additionally be reduced through the production of networks of electrically conducting magnetite ${ }^{29}$. The reduction in resistivity of the upper mantle from values exceeding $1,000 \Omega \mathrm{m}$ to approximately $50 \Omega \mathrm{m}$ on bending as observed in our study (anomaly C in Fig. 2) is in agreement with laboratory experiments on dry and serpentinized mantle rocks ${ }^{29}$.

Farther landward in the subduction process, hydration is superseded by dehydration. Two mechanisms account for fluid release in the subduction channel, that is, the region between the subducting and overriding plates. (1) Expulsion of free fluids from gradually closing fractures and pore spaces along the upper few kilometres of the subduction channel. (2) Release of mineral-bound water along the deeper portion of the subduction channe ${ }^{23}$. We cannot structurally resolve the subduction channel with magnetotellurics, but we can image fluid accumulations associated with dehydration processes in the subduction channel. The expulsion of free fluids is documented in a shallow, not well-resolved, very conductive (low-resistive) zone along the décollement zone (in Fig. 2 red-coloured region positioned at $130-160 \mathrm{~km}$ between anomalies $\mathrm{C}$ and $\mathrm{D}$ ). Release of mineralbound water is most probably associated with the distinct and 


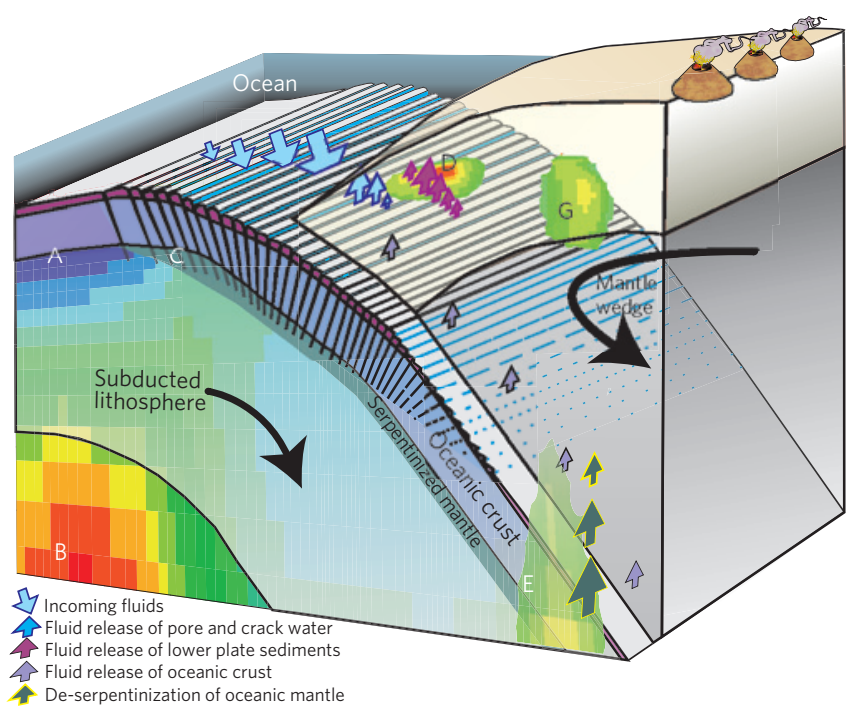

Figure 3 | Schematic interpretation of inversion results. Straight arrows indicate different pathways and origins of fluids. The cool incoming plate (A) is topped by water-saturated sediments (pink layer on top of subducting slab) and overlays a hot asthenosphere (B). On bending, the oceanic crust is hydrated possibly to upper-mantle depths (C). Anomaly D is associated with release of mineral-bound water and $\mathrm{G}$ with accumulation of crustal fluids caused by fluid release within the oceanic crust or heating and dewatering of the mantle wedge. The weakly resolved anomaly $\mathrm{E}$ can be associated with de-serpentinization of oceanic mantle.

well-resolved anomaly $\mathrm{D}$ at $12-15 \mathrm{~km}$ depth, where resistivity values drop from around 50 to $5-10 \Omega \mathrm{m}$. This depth corresponds to the geochemically derived source depth of fluids produced through clay demineralization, which flow upward along deepseated faults and exit at mid-slope fluid seeps. Although we do not directly detect such an upward fluid flow owing to limited resolution, mid-slope fluid seeps are indeed observed along our profile (see Fig. 1). Estimates derived from the resistivity values and anomaly size are compatible with a fluid volume of $1-6 \mathrm{~km}^{3}$ per km of along-strike trench, which would amount to about $5-34 \%$ of the fluids that are estimated to have entered the subduction zone over the past $10 \mathrm{Myr}$ on the basis of information from Ocean Drilling Program leg 170 (see Supplementary Information).

Underneath anomaly D a cluster of earthquakes defining the seismogenic zone ${ }^{25}$ is observed, showing that the transition from aseismic to seismogenic behaviour correlates with a declining amount of fluid ${ }^{30}$.

Further prominent conductivity anomalies are revealed by the land data. The high-conductivity zone located $\sim 150 \mathrm{~km}$ landward of the trench, at $30 \mathrm{~km}$ distance to the volcanic arc at $\sim 20-30 \mathrm{~km}$ depth, is termed anomaly $G$ in accordance with ref. 9. The temperature at this depth is not sufficiently high to produce or retain substantial melt fractions. This anomaly is most probably associated with fluid release from the oceanic crust ${ }^{2}$ or heating and dewatering of the upper part of the serpentinized mantle wedge. Our estimate on the basis of the size and resistivity of the anomaly amounts to $0.5-2.5 \mathrm{~km}^{3}$ of fluid per kilometre trench length (see Supplementary Information).

Their preliminary resistivity modelling ${ }^{9}$ required a highresistivity zone underneath anomaly G. However, by adding offshore data and not applying horizontal smoothing during the inversion as previously done, we now find that a zone of reduced resistivity (anomaly E beneath $70 \mathrm{~km}$ under anomaly $\mathrm{G}$ ) proves stable in the inversion process.

Resolution tests confirm a slightly better fit for a reducedresistivity zone below $70 \mathrm{~km}$ depth in the current study (see Supplementary Information). The transparent faded region in Fig. 2 indicates where sensitivity is reduced in the model. However, numerical models showing an effective dehydration of serpentinized mantle and crust (de-serpentinization) at more than $100 \mathrm{~km} \mathrm{depth}^{2}$ suggest that this anomaly is geochemically feasible and could therefore be associated with de-serpentinization.

The diagram in Fig. 3 summarizes the interpreted hydrationdehydration cycle: in the hydration part on bending, deep faults are created, enabling water to penetrate to mantle depths (C). Water is partially stored in cracks and pores (free fluids) as well as mineral (chemically) bound in oceanic sediment, crust and (serpentinized) mantle. In the dehydration part, on subduction farther downward, water is released and expelled from cracks and pores within the first few kilometres. Additionally, water released from shallow phase transition reactions in sediment is accumulated at shallow depths (D). Further in the subduction process, crustal and mantle dehydration
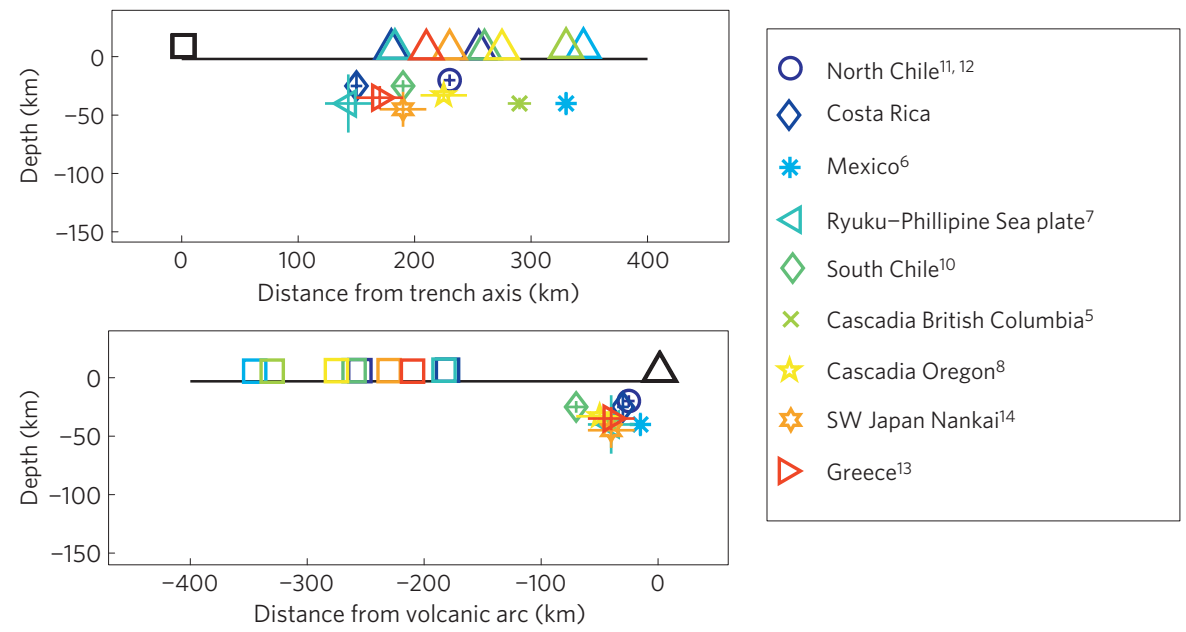

Figure 4 | Global overview of the forearc conductor (anomaly G) appearances in subduction zones. Triangles depict the volcanic arc; squares represent the trench axis; colours correspond to different subduction zones (see the legend on the right). Error bars are assigned according to the uncertainty of the centre of the conductive zone. See Supplementary Information for further details. Upper left panel: distances of anomalies $\mathrm{G}$ and volcanic arcs from trench axes are plotted (trench axes are aligned to zero). Lower left panel: distances of anomalies $\mathrm{G}$ and trench axes from volcanic arcs are plotted (volcanic arcs are aligned to zero). 
are associated with deep-crustal fluid accumulation (G). An effective dewatering through de-serpentinization at depths greater than $\sim 100 \mathrm{~km}$ might be associated with a weakly resolved anomaly at depth (E).

Anomaly $\mathrm{G}$ in the overriding plate deserves more attention, because comparable anomalies of varying resolution are observed in mature subduction zones that have developed typical surface expressions such as volcanic arcs around the world: land magnetotellurics surveys in South Chile ${ }^{10}$, in British Columbia ${ }^{5}$ and in Oregon $^{8}$ (Cascadia), in Mexico ${ }^{6}$, in North Chile $\mathrm{e}^{11,12}$, in Greece ${ }^{13}$ and in Japan (Nankai) ${ }^{14}$, as well as a marine magnetotellurics survey in Japan (Ryukyu Trench) ${ }^{7}$, image conductive (low-resistive) zones in comparable distances to the volcanic arcs. The observed anomalies are summarized in Fig. 4; they are located in similar distances from volcanic arcs and are located at similar depths (20-40 km from volcanic arcs in 20-40 km depth, except for outlier South Chile). Details on the various subduction zone anomalies are given in the Supplementary Information.

The conductivity anomaly $\mathrm{G}$ thus represents a globally existent fluid accumulation and must be linked to fundamental dynamical processes in subduction zones. Output fluxes determined for the forearc fluid venting and the volcanic arc emissions typically account for less than half of the input flux of free or mineral- and chemically bound fluids in subducting sediment and hydrated crust and mantle, although volatile losses from intrusive magmatism are very poorly constrained ${ }^{4}$. Numerical modelling of fluid release during metamorphic reactions in the subducting slab suggests that $20-40 \%$ of the water input may be transferred into the deep mantle ${ }^{2}$. These numbers indicate that a fraction of about $10-30 \%$ of the water input flux is not yet accounted for; therefore, a possible extra sink for water flux may be these forearc conductivity anomalies (G).

Our study images fundamental hydration and dehydration processes of subduction zones beyond a regional scale. Hydration and serpentinization of the upper mantle ${ }^{16,18}$ and effective dewatering of slab components in distinct steps $s^{2,6}$ have been proposed previously using different data and modelling schemes. Our results synergize these aspects into a geographically and methodologically unifying model of the fluid cycle through subduction zones in its entirety.

Furthermore, our findings suggest a possible global fluid sink in the forearc (anomaly $G$ ) that may account for the discrepancies between input and output flux along subduction zones.

\section{Method summary}

Magnetotellurics is a passive electromagnetic geophysical method for imaging the electrical-resistivity structure (reciprocal to conductivity) of the subsurface.

Naturally occurring fluctuations of the Earth's magnetic external field induce electric currents whose strength and distribution depend on the subsurface resistivity. Variations of the horizontal electric and three-component magnetic fields are recorded on the ocean bottom and land surface to derive a spectral, complex-valued impedance tensor $\underline{Z}$ given by $\underline{Z} \cdot \mathbf{H}_{\mathrm{h}}=\mathbf{E}_{\mathrm{h}}$ where $\mathbf{E}_{\mathrm{h}}$ and $\mathbf{H}_{\mathrm{h}}$ denote the frequency-dependent horizontal electric $\left(\overline{\overline{\mathbf{E}_{\mathrm{h}}}}\right)$ and magnetic $\left(\mathbf{H}_{\mathrm{h}}\right)$ fields. An extra spectral, complex-valued transfer function, the magnetic tipper $\vec{T}$ is given by $T \cdot \mathbf{H}_{\mathrm{h}}=H_{\text {vertical }}$. In a homogenous half-space, the so-called skin depth $\delta$ is a crude estimate of detection depth with $\delta \approx 0.5 \sqrt{\rho t}$ in kilometres (where $t$ is the period and $\rho$ is the bulk resistivity). At periods shorter than approx. $1 \mathrm{~s}$, seafloor electromagnetic signals are very small. This is due to the high conductivity of the sea water above, which causes attenuation according to skin depth and thus reduces the resolvability of shallower sea-bottom features.

In a perfect two-dimensional setting, the strike-rotated complex impedance tensor contains only off-diagonal elements, which show two decoupled modes: the transverse-electric mode, that is, electric field parallel to strike, and the transverse-magnetic mode, that is, magnetic field parallel to strike. The transverse-electric and transverse-magnetic impedance transfer functions and the tipper contain information on the resistivity (or conductivity) distribution within the Earth and are used as input data for modelling.

For the offshore campaign we used marine magnetotellurics instruments newly developed at IFM-GEOMAR and the University of Kiel. The marine instruments contain, in addition to a three-component fluxgate magnetometer and two $E$-field channels, a dual-axis tilt meter for measuring pitch and roll (the displacement from the horizontal). The period bandwidths of the marine responses

vary owing to the depth-dependent absorption effect of the conductive ocean as well as motion-induced noise through tidal currents and waves.

The motion-induced noise was directly visible through the tilt-meter measurement, which showed strongest motion close to the coast: station $m 01$ eventually tilted beyond measurement range and station $m 02$ was even lost (see Supplementary Fig. S2 for positions). We cut out all noisy sections as defined by the tilt-meter measurements and only used time-series sections that were uncorrelated to the tilt variations and at the same time coherent with a reference station. This resulted in shorter sections for stations close to the coast, which were more affected by tidal waves (and therefore show shorter periods in comparison to stations farther offshore, as can be seen in Supplementary Fig. S3). Nevertheless, a long recording time of several months enabled the selection of many sections, which were then processed together.

The onshore campaign was carried out by ref. 9. Dimensionality and strike analysis of land data proved the validity of a two-dimensional assumption and determination of strike angle. More technical details and resolution tests are provided in the Supplementary Information.

\section{Received 3 March 2010; accepted 19 November 2010;} published online XX Month XXXX

\section{References}

1. Peacock, S. A. Fluid processes in subduction zones. Science 248, 329-337 (1990).

2. Ruepke, L. H., Morgan, J. P., Hort, M. \& Connolly, J. A. D. Serpentine and the subduction zone water cycle. Earth Planet. Sci. Lett. 223, 17-34 (2004).

3. Hacker, B. R., Peacock, S. M., Abers, G. A. \& Holloway, S. D. Subduction factory 2. Are intermediate-depth earthquakes in subducting slabs linked to metamorphic dehydration reactions? J. Geophys. Res. 108, 2030 (2003).

4. Jarrard, R. D. Subduction fluxes of water, carbon dioxide, chlorine, and potassium. Geochem. Geophys. Geosyst. 4, 8905 (2003).

5. Soyer, W. \& Unsworth, M. Deep electrical structure of the northern Cascadia (British Columbia, Canada) subduction zone; implications for the distribution of fluids. Geology 34, 53-56 (2006).

6. Joedicke, H. et al. Fluid release from the subducted Cocos plate and partial melting of the crust deduced from magnetotelluric studies in southern Mexico: Implications for the generation of volcanism and subduction dynamics. J. Geophys. Res. 111, B08102 (2006).

7. Shimakawa, Y. \& Honkura, Y. Electrical conductivity structure beneath the Ryukyu trench-arc system and its relation to the subduction of the Philippine sea plate. J. Geomagnetism Geoelectricity 43, 1-20 (1991).

8. Jiracek, G. R., Curtis, J. H., Ramirez, J., Martinez, M. \& Romo, J. Two-dimensional magnetotelluric inversion of the EMSLAB Lincoln line. J. Geophys. Res. 94, 14145-14152 (1989).

9. Brasse, H. et al. Deep electrical resistivity structure of northwestern Costa Rica. Geophys. Res. Lett. 36, L02310 (2009).

10. Brasse, H. et al. Structural electrical anisotropy in the crust at the South-Central Chilean continental margin as inferred from geomagnetic transfer functions. Phys. Earth Planet. Inter. 173, 7-16 (2009).

11. Schwalenberg, K., Haak, V. \& Rath, V. The application of sensitivity studies on a two-dimensional resistivity model from the Central Andes. Geophys. J. Int. 150, 673-686 (2002).

12. Brasse, H. et al. The Bolivian Altiplano conductivity anomaly. J. Geophys. Res. 107, doi:10.1029/2001JB000391 (2002).

13. Galanopoulos, D., Sakkas, V., Kosmatos, D. \& Lagios, E. Geoelectric investigation of the Hellenic subduction zone using long period magnetotelluric data. Tectonophysics 409, 73-84 (2005).

14. Ichiki, M., Sumitomo, N. \& Kagiyama, T. Resistivity structure of high-angle subduction zone in the southern Kyushu district, southwestern Japan. Earth Planet. Space 52, 539-548 (2000).

15. Mével, C. Serpentinization of abyssal peridotites at mid-ocean ridges. C. R. Geosci. 335, 825-852 (2003).

16. Ranero, C. R., Morgan, J. P., McIntosh, K. \& Reichert, C. Bending-related faulting and mantle serpentinization at the Middle America trench. Nature 425, 367-373 (2003).

17. Grevemeyer, I. et al. Heat flow and bending-related faulting at subduction trenches: Case studies offshore of Nicaragua and Central Chile. Earth Planet. Sci. Lett. 236, 238-248 (2005).

18. Faccenda, M., Gerya, T. V. \& Burlini, L. Deep slab hydration induced by bending-related variations in tectonic pressure. Nature Geosci. 2, 790-793 (2009).

19. Schmeling, H. Numerical models on the influence of partial melts on elastic, anelastic and electrical properties of rocks. Part II: Electrical conductivity. Phys. Earth Planet. Inter. 43, 123-136 (1986).

20. Wannamaker, P. E. et al. Fluid and deformation regime of an advancing subduction system at Marlborough, New Zealand. Nature 460, 733-736 (2009).

21. Evans, R. L. \& Chave, A. D. On the importance of offshore data for magnetotelluric studies of ocean-continent subduction systems. Geophys. Res. Lett. 29, 9 (2002). 
22. Wannamaker, P. E. et al. Resistivity cross section through the Juan de Fuca subduction system and its tectonic implications. J. Geophys. Res. 94, 14127-14144 (1989).

23. Hensen, C., Wallmann, K., Schmidt, M., Ranero, C. R. \& Suess, E. Fluid expulsion related to mud extrusion off Costa Rica- a window to the subducting slab. Geology 32, 201-204 (2004).

24. Husen, S., Quintero, R., Kissling, E. \& Hacker, B. Subduction-zone structure and magmatic processes beneath Costa Rica constrained by local earthquake tomography and petrological modeling. Geophys. J. Int. 155, 11-32 (2003).

25. DeShon, H. R. et al. Seismogenic zone structure beneath the Nicoya Peninsula, Costa Rica, from three-dimensional local earthquake P- and S-wave tomography. Geophys. J. Int. 164, 109-124 (2006).

26. Baba, K., Chave, A. D., Evans, R. L., Hirth, G., Mackie, \& R. L., Mantle dynamics beneath the East Pacific Rise at 17_S: Insights from the Mantle Electromagnetic and Tomography (MELT) experiment. J. Geophys. Res. 111, B02101 (2006).

27. Constable, S. C. \& Duba, A. The electrical conductivity of olivine, a dunite, and the mantle. J. Geophys. Res. 95, 6967-6978 (1990).

28. Heinson, G. Electromagnetic studies of the lithosphere and asthenosphere. Surveys Geophys. 20, 229-255 (1999).

29. Stesky, R. M. \& Brace, W. F. Electrical conductivity of serpentinized rocks to 6 kilobars. J. Geophys. Res. 78, 7614-7621 (1973).

30. Ranero, C. R. et al. Hydrogeological system of erosional convergent margins and its influence on tectonics and interplate seismogenesis. Geochem. Geophys. Geosyst. 9, Q03S04 (2008).

\section{Acknowledgements}

This publication is contribution No 187 of the Sonderforschungsbereich 574 'Volatiles and fluids in subduction zones' at Kiel University. The logistical support of Guillermo Alvarado and the Instituto Costarricense de Electricidad is appreciated. We would further like to thank the Costa Rican Coast Guard for providing us with ship time and the German embassy in Costa Rica for intercession. We thank B. Lewitz, Y. Dzierma, R. Kroth, P. Schroeder, T. Brandt and C. Jung for their great help in the campaign. We also thank D. Scholl and two anonymous reviewers for comments that helped to substantially improve this paper. Thanks to A. Freundt and S. Kutterolf for discussions. The study was funded by the German Science Foundation.

\section{Author contributions}

T.W. and M.J. designed this study, developed marine magnetotellurics instruments, carried out the marine experiment, analysed the data, interpreted the results and wrote the paper; H.K. interpreted the results and wrote the paper; H.B. designed this study, carried out the land experiment, analysed the data and interpreted the results; W.T. provided geologic background information and logistical support, which was vital for the whole experiment.

\section{Additional information}

The authors declare no competing financial interests. Supplementary information accompanies this paper on www.nature.com/naturegeoscience. Reprints and permissions information is available online at http://npg.nature.com/reprintsandpermissions. Correspondence and requests for materials should be addressed to T.W. 


\section{Page 1}

Query 1: Line no. 10

As per journal style, reference citations should be in numerical order. Therefore references are renumbered from here onwards. OK?

Query 2: Line no. 26

Please note that the first paragraph has been edited according to style.

Query 3: Line no. 27

Please provide post codes for affiliations 3 and 4.

\section{Page 3}

Query 4: Line no. 13

'ODP' changed to 'Ocean Drilling Program'-is this correct?

Query 5: Line no. 54

A closing bracket deleted from figure 4. Please check.

\section{Page 4}

Query 6: Line no. 52 ' $\vec{T}$ '.

' $T$ ' is given in the text. Please confirm this is not

Query 7: Line no. 95

Please provide page range/aritcle id for refs $3,4,12,21$. 